\title{
Extended differential conditioning of the classically conditioned eyeblink reflex
}

WILLIAM R. MUIR AND WILLARD N. RUNQUIST

UNIVERSITY OF ALBERTA

\begin{abstract}
Twenty Ss were given 60 reinforced trials to a positive CS and 60 non-reinforced trials to a negative $\mathrm{CS}$ on each day for five days. An increase in frequency of CR to both CSs but no discrimination was found on Day-1. On Day-2, performance to both CSs levelled off and discrimination began. On Days 3-5, discrimination improved between but not within daily sessions. With each of these sessions there was a decrease in frequeincy of CRs to both positive and negative CSs over trials.

\section{Purpose}

Previous studies of differential conditioning of the eyeblink response (Hartman \& Grant, 1962) and the GSR (Kimmel \& Pennypacker, 1963) have indicated that discrimination performance is superior with longer CS-UCS intervals, and that for the shorter 500-msec. interval which usually produces maximal conditioning performance in regular classical procedures very little differentiation between positive and negative stimuli is obtained. Since the number of reinforced trials in these studies was quite small, it is possible that discriminations can be developed with short CS-UCS intervals, but that the rate of development of the discrimination is slower. Thus, one purpose of this study was to determine the course of development of differential conditioning with training extended over a large number of trials.

A second purpose of the experiment concerned the finding of Runquist \& Muir (1965) that when Ss were given 100 conditioning trials per day for five days, their performance increased between days but dropped within each daily session. The present study attempted to determine whether these intrasession decrements would also occur in the more complex discrimination situation.

\section{Method}

The apparatus for classically conditioning the eyeblink reflex has been described elsewhere (Runquist \& Muir, 1965). The Ss were 20 undergraduater paid for their services and run alone or in pairs. Each $\mathrm{S}$ was seated in an individual booth and given neutral instructions to relax, fixate a point at eye level and respon ' naturally. The two CSs were tones of 450 and 700-cps presented to $S$ through earphones with an intensity of .05- $v$. The UCS was a puff of compressed nitrogen to the cornea of the right eye of $75-\mathrm{msec}$. duration under a pressure of $80-\mathrm{mm}$ (mercury). A CS-UCS interval of $525-\mathrm{msec}$. was used with a CR defined as a blink occurring between 150-500 msec. following CS onset.
In each daily session, Ss received 60 reinforced presentations of the positive $\mathrm{CS}(\mathrm{S}+)$ and 60 presentations of the negative CS (S-) with the UCS omitted. Thus, over all five sessions there were 300 reinforced trials. Ten Ss had the 450 -cps tone as S+, while 10 Ss had the 700-cps tone as S+:

\section{Hesults}

The per cent CR's to S+ and S- over all days is shown in ten trial blocks in Fig. 1. It is apparent that little differentiation between the two stimuli took place until the end of the second session, but differences henceforth were quite marked. Evaluation of differences in performance was made by analysis of variance, with the first comparisons being separate analyses within each day, being carried out as a Trials by CS factorial design. Although the two different groups using the different tones as S+ occasionally performed differently, none of the effects were of theoretical interest so these groups were combined for these and other analyses. On Day-1, only Trials was significant, $\mathrm{F}(5,209)=5.79, \mathrm{p}<.01$. On Day-2, the Trials by CS interaction was significant, $F(5,209)=3.06, p<.05$, as well as the main effect of $\mathrm{CS}, \mathrm{F}(1,209)=15.93, \mathrm{p}<.001$. On Days 3-5, the CS effect was significant, $F(1,209)=28.34,68.20$, and 109.48 respectively, all $\mathrm{p}<.001$. In addition, on Day-3, Trials was also significant, $F(5,209)=2.54, p<.05$. These results then

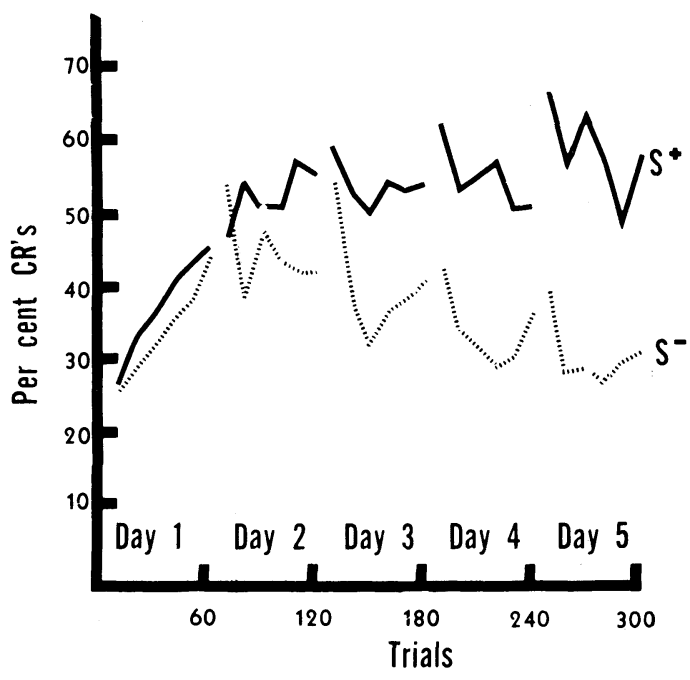

Fig. 1. Per cent CR's in blocks of 20 trials. 
support the general trends suggested in Fig. 1. Discrimination began on Day-2 and continued through the final session.

Although Fig. 1 suggests that intrasession decrements occurred to both S+ and S- on Days 3-5, the only significant losses took place on Day-3. A separate analysis of the post discrimination data (Days 3-5) as a Days by Trials by CS factorial design resulted in significant effects of Trials $F(5,665)=5.06, p<.01$; CS, $F(1,665)=181.58, p<.01$; and Days by CS, $\mathrm{F}(2,665)=6.76, \mathrm{p}<.01$. Since the mean response to S+ increased monotonically and to S- decreased monotonically over Days $3-5$, it is clear that discrimination improved over the last three daily sessions. To extract more information concerning the changes within sessions, separate trend analyses were run on the S+ and Sfunctions within these days. For the S+ only the linear component of the intrasession decrement was significant, $F(1,323)=7.86, p<.01$, while to the $S-$, both linear and quadratic components were significant, $F(1,323)=4.95$ and 16.82 respectively. It would thus appear that the decrements within the last three sessions took a different course for the two stimuli.

\section{Discussion}

The data were clear in indicating that differential conditioning can be established at short CS-UCS intervals providing training is carried out long enough. If, as Hartman \& Grant (1962) suggest, verbalization of the reinforcement contingency is responsible for differentiation at long CS-UCS intervals, these results can be interpreted in two ways. Either mediation mechanisms are not responsible for the discrimination at short CS-UCS intervals, or with extended training the mediators occur with short enough latency to produce successful discrimination. The results were also clear in indicating within session decrements in performance to both S+ and S-. Moreover, the pattern of results suggests that differentiation between stimuli is maximal in the middle of the session. Although it is not possible to evaluate the reliability of the increases in responding to $\mathrm{S}$ - toward the end of the session, this result did appear on each of the last three days. It has been suggested (Runquist \& Muir, 1965; Runquist \& Towart, 1966) that these decrements are due to inattention to the CS. According to this hypothesis, not only does inattention produce CR failures to the S+ but also failure to discriminate between $\mathrm{S}+$ and $\mathrm{S}-$ with the resultant increase in response to the negative stimulus. Other interpretations are, of course, possible but based on this and previous studies the "vigilance" hypothesis seems most promising at the present time.

\section{References}

Hartman, T. F., \& Grant, D. A. Differential eyelid conditioning as a function of the CS-UCS intervai. J. exp. Psychol., 1962, 64, 131-136.

Kimmel, H. D., \& Pennypacker, H. Differential GSR conditioning as a function of CS-UCS interval. J. exp. Psychol., 1963, 65, 559-563.

Runquist, W. N., \& Muir, W. R. Intrasession decrements in the performance of the classically conditioned eyelid reflex. J. exp. Psychol., 1965, in press.

Runquist, W. N., \& Towart, E. M. Further evidence for intrasession decrements in eyelid conditioning. Psychol. Rep., 1966, in press. Note

1. Supported by NIH Grant HD $0047-01$. 